\title{
THERMAL CONTROLS ON OCEANIC LITHOSPHERE DEHYDRATION AND FLUID FLUX TO THE MANTLE DURING SUBDUCTION
}

CAIley B. CONDIT ${ }^{1}$, AdAm F. HolT ${ }^{2}$, Victor E. GUEVARA $^{3}$, JONATHAN R. DELPH ${ }^{4}$, MELODIE E. FRENCH $^{5}$,

${ }^{1}$ University of Washington, Seattle WA; ccondit@uw.edu ${ }^{2}$ University of Miami, Miami, FL; aholt@miami.edu

${ }^{3}$ Amherst College, Amherst MA; vguevara@amherst.edu

${ }^{4}$ University of Oregon, Eugene OR; jdelph@oregon.edu

${ }^{5}$ Rice University, Houston, TX; mefrench@rice.edu

Subduction margins are the primary location of fluid delivery to the mantle. Hydrated oceanic lithosphere releases water from the trench to sub-arc depths and beyond through metamorphic breakdown of hydrous minerals. As pressure and temperature increase, metamorphic reactions release aqueous fluid, which strongly influences subduction zone slip behaviours, serpentinization, flux melting beneath the arc, and the amount of fluids delivered deeper into the mantle. We present thermodynamic models of hydrated MORB and depleted MORB mantle (DMM) coupled to subduction zone thermal structures, from both published kinematic models and our own dynamic, time-dependent subduction models. We use these models to predict where major dehydration occurs and to understand the relationship of fluid production to geophysical observations. This approach reveals a strong spatial relationship between MORB dehydration and the occurrence of tremor and episodic slow slip in warm subduction zones. Our models also show that over the maturation of a subduction zone, the evolving thermal structure enacts a first order control on which portion of the lithosphere is dehydrating at sub arc depths, with DMM providing fluids in young, warm subduction zones. In older, colder subduction zones, MORB along the slab top dehydrates at sub arc depths, and DMM remains thermally insulated, carrying significant amounts of mineral-bound water into the mantle well past the arc. 